In a written answer in the House of Commons on January 23, Mr. Carr stated that since March 1962 the British Council had made grants totalling $£ 43,000$ to assist public library development projects in Northern Nigeria, Uganda and Zanzibar. A further grant to Fiji was under consideration, and assistance had also been given to a library training scheme at Makerere University College. Four scholarships and 6 bursaries for study in Britain had been granted to student librarians from the Gambia, Jamaica, India, Malaysia, Nyasaland, Pakistan (3), Sabah and Zanzibar, and 8 more had attended a summer school on librarianship arranged by the British Council in Britain in September 1962. Five United Kingdom librarians had been recruited since March 1962 for Fiji, Tanganyika (2), Northern Rhodesia and Nyasaland. A booklet outlining the requirements of United Kingdom professional bodies in engineering and building had been produced in consultation with the professional institutions concerned and was being distributed overseas to college principals and others.

\section{Personality Factors in Intellectual Development}

THE Nuffield Foundation has recently made a grant of $£ 20,500$ over five years to Dr. Liam Hudson, of the Psychological Laboratory, University of Cambridge, for research into personality factors in intellectual development. During the past six years, Dr. Hudson has been collecting evidence about the differences in intelligence and in personality between arts and science specialists in the sixth forms of English boys' schools. He has found that young scientists show a bias of ability towards conventional tests of intelligence, whereas the arts specialists' bias is towards 'open-ended' tests having many possible and equally correct answers. Recent American research suggests a connexion between ability on the latter type of test and originality in all fields, including science. The implication is that most potentially original sixth-formers in English schools prefer arts to science subjects. Dr. Hudson found marked correlations between scores on the two types of test and particular personality traits. $\mathrm{He}$ now plans to pursue his work further, and to try to discover more about the effects of these traits on intellectual development.

\section{The British Broadcasting Corporation}

A NOTE on "prudent management" of the British Broadcasting Corporation's finances, issued as B.B.C. Record, No. 24 (January 1964), makes a startling footnote to the debate in the House of Commons on January 14. While the Corporation's reserves fell only from $£ 3,159,000$ to $£ 2,830,000$ in the eight years March 31,1954 , to March 31,1962 , and operating costs per hour rose by 40 per cent for home services and 47 per cent for external broad. casting, income for radio and television increasing by 160 per cent, in the following year reserves fell by $£ 2,700,000$, chiefly through the gross expenditure of $£ 1,850,000$ (mainly capital) incurred in preparing for the second television service and other developments. On the other hand, while a further $£ 250,000$ had to be provided from reserves for increased fees to artists, the rise in income is levelling off. Television costs per hour have risen by 140 per cent, and the note insists that rising costs and expenditure cannot be met on the basis of the existing licence fees.

\section{University News:}

Aberdeen

Dr. C. St. J. A. Nash-Williams has been appointed senior lecturer in the Department of Mathematics; M. H. Chapman has been appointed lecturer in engineering.

London

Srr Cyrim Hinshelwood, Nobel Laureate and pastpresident of the Royal Society, has been appointed to a senior research fellowship at the Imperial College of Science and Technology from October 1964 on his retirement from the Dr. Le日's ehair of chemistry at the University of Oxford.

Dr. E. R. Laithwaite, senior lecturer in the University of Manchester, has been appointed to the chair of heavy electrical engineering tenable at the Imperial College of Science and Technology from October 1. Dr. F. R. Whatley, associate plant physiologist in the University of California, has been appointed to the chair of botany tenable at King's College from April 1.

\section{Sheffield}

Av illustrated brochure describing briefly the University of Sheffield, its history and development and the development plan to 1968, includes a few figures for research expenditure (The University of SheffieldDescriptive Brochure. Pp. 24. Sheffield: The University, 1963). The total revenue from research grants and contracts from Government departments, research councils, foundations, industry, etc., rose from $£ 220,802$ in $1960-61$ to $£ 253,377$ in $1961-62, £ 81,955$ and $£ 82,650$, respectively, of this coming from the Research Councils. The University's own expenditure on research is not stated, but the total postgraduate population has doubled in the past ten years.

\section{Baird and Tatlock's New Bench Centrifuge}

IN the advertisement on the front cover of Nature of January 11, describing and illustrating the new bench centrifuge devised by Messrs. Baird and Tatlock (London), Ltd, the following information was inadvertently omitted: "Catalogue No. C6/0075 B.T.L. Bench Centrifuge. Price $£ 48$ 15s. Od. (without heads, trunnions or buckets). Please write for leaflet $T 126 / J^{\prime}$. The main address of this firm is: Baird and Tatlock (London), Ltd., Chadwell Heath, Essex, England.

\section{Announcements}

DR. J. E. RICHEy, lecturer in geology, Queen's College, Dundee, has been awarded the Clough Medal for the period 1963-64 by the Edinburgh Geological Society. Dr. Richey has made many important contributions to the understanding of the geology of Scotland, none more outstanding than his pioneer investigations of Tertiary Ring Complexes of the Brito-Arctic Province.

A CONFERENCE on "Rubber and Plastics in Road Transport", arranged jointly by the Institution of the Rubber Industry and the Plastics Institute, will bo held in Oxford during April 7-8. Further information can be obtained from the Secretary, the Plastics Institute, 6 Mandeville Place, London, W.1.

The Silver Jubilee Conference of the Natural Rubber Producers' Research Association will be held in Cambridge during April 7-9. Two discussion symposia will be held on "Ultrastructure and Metabolism of Hevea Latex" and "Chemical Structure and Mechanical Properties of Vulcanized Rubber". Further information can be obtained from Mr. H. Rodway, Natural Rubber Producers' Research Association, 19 Buckingham Street, London, W.C.2.

A JorNT meeting of the Biochemical Society and the Association of Clinical Biochemists will be held in the University College of South Wales and Monmouthshire during February 28-29. The meeting will include a colloquium on "Carbohydrate Sulphate Esters of Animal Origin" and a symposium on "Glycoproteins and Mucoproteins of the Body Fluids". Further information can be obtained from the meetings secretary of the Biochemical Society, Dr. H. R. V. Arnstein, National Institute for Medical Research, The Ridgeway, Mill Hill, London, N.W.7. 